San Antonio Review •

\title{
creative writing: insideout
}

William O. Pate II, Inside Books Project

Published on: Nov 01, 2021

License: Creative Commons Attribution 4.0 International License (CC-BY 4.0). 


\section{Table of Contents}

Introduction

Creative Writing.

Fiction

Creative Nonfiction

$\underline{\text { Poetry }}$

\section{Introduction}

\section{Purpose}

What' s the point of writing? Especially creative writing? It doesn' t deal with the real or what happens every day. It doesn' thelp you get a job, like professional writing does. Even worse: It' s hard. That blank white page truly is a tyrant. Where do I start? And how?

\section{How to Use This Book}

When it comes to fighting that blank page and getting the first words down, you may feel like pencilwielding David fighting a paper Goliath. Don' t worry. There' s no correct - or incorrect - way to write or to use this book. Take what you need and leave the rest, as they say. Ultimately, this book is worthless without your interaction. That means, writing.

\section{The Reality}

In reality, everyone has a story to tell. Your spelling may be bad, your grammar or usage may be off and you may think you have nothing to say. You' 11 find out otherwise once you begin fighting the tyrant and putting words on these pages.

\section{Creative Writing}

Creative writing can take many forms - from a personal essay to a poem. You can write stories, sonnets and songs. These are all forms of creative writing.

Many times, that tyranny of the blank page hits and you just can' t get started. A great way to combat this is by writing whatever comes into your head and seeing where it goes. 
This is called stream of consciousness writing - a form of brainstorming that can be used for any writing task and that has also been used to write entire books (see: Jack Kerouac' s On the Road).

Being a writer is a very peculiar sort of a job: it's always you versus a blank sheet of paper (or a blank screen) and quite often the blank piece of paper wins. -Neil Gaiman

\section{Stream of Consciousness Writing}

When you' re writing this way, try to let the words flow from your mind down your arm through your fingers into the pen and onto the page. You should consider this personal writing - for your eyes only. You can write anything. It doesn' t need to make sense. Somewhere inside that jumble of words, you' 11 likely find a nugget or two (or more) of ideas to pursue in your writing.

\section{Your Turn}

\section{Don' t Be Perfect}

You don' t need to be perfect. Creative writing isn' t about perfection. It' $s$ about creativity. There are no real rules. This exercise may help you realize that. Let your thoughts flow and write.

\section{Your Turn}




\section{Stream of Consciousness Exercise}

Let the sentences in your head flow onto the page without censoring yourself. Write.

\section{Fiction}

\section{What Is It?}

Mostly, fiction is untrue. It' s what most people think of when they hear the words, "creative writing."

"Your company is the greatest. I can' t imagine anyone living without you." -Very smart customer

\section{Write What You Know}

Many writers will tell you that it is easiest to write about the things with which you already have experience. It' $s$ much easier than trying to describe what it' $s$ like on the moon if you' ve actually been there. You can use your experiences and the people you know as starting points.

\section{Show, Don't Tell}

Teachers say it all the time, and it is true. The best writing shows readers the characters and stories; it doesn' t just tell. Instead of saying a character is sad, one could describe the tears on her cheek. The same message is communicated but one is more original than the other.

\section{Your Turn}




\section{Fiction Exercise}

Like most writing, fiction can come in many forms and sizes - from short stories to novels. Some short stories are only a paragraph long (see Lydia Davis or Etgar Keret, for example)! Below, try your hand at writing a fictional story.

\section{Your Turn}

\section{Fiction Exercise}

Write a story that revolves around a mysterious phone call.

\section{Your Turn \\ Fiction Exercise}

Try making up a story. Create your own characters and situations. Most important, make it personal. It will be easier to write if it means something to you.

\section{Creative Nonfiction}

\section{What Is It?}

Creative nonfiction encompasses a wide variety of literature - from personal essays to coverage of real events in a creative manner. A couple of examples of personal essays are 
writing about an experience you' ve had or a book you' ve read. Writing true stories as creative nonfiction usually involves adding, subtracting and molding the story - adding drama, removing unneeded characters, reshaping what happened so it's more interesting. In fact, in creative nonfiction, just like in fiction, you can make up entire parts of the story. That's what makes it creative and not just another nonfiction book.

As Annie Dillard writes,

I was delighted to find that nonfiction prose can also carry meaning in its structures, can tolerate all sorts of figurative language, as well as alliteration and even rhyme. The range of rhythms in prose is larger and grander than it is in poetry, and it can handle discursive ideas and plain information as well as character and story. It can do everything.

\section{Your Turn}

\section{Creative Nonfiction Exercise}

Try taking something from your life and creatively writing about it. Or write an essay. Just write.

\section{Your Turn}

\section{Creative Nonfiction Exercise}

\section{Sense Association}

Write about the sense (sight, smell, touch, hearing and taste) that affects you most strongly.

OR

\section{Important Place}

What place holds the strongest emotion for you? Free write about the place. 


\section{Your Turn}

\section{Creative Nonfiction Exercise}

Write about something you know - but make it a good story. That can include making pieces of it fictional: Adding, subtracting or consolidating characters, changing the place, changing actions and more.

\section{Poetry}

\section{What Is It?}

Most people would view poetry as being completely different from fiction or creative nonfiction prose. That' s not entirely true. Poems, like the other forms of creative writing, come in many shapes and sizes.

Poems don' thave to rhyme or have a certain number of stanzas. Poetry is like music, too, in that it can make people feel emotions through the sound and rhythm of the words as well as their meaning.

Some poems are as long as books; others are only a couple of lines. 
The rule for all writing is that it only needs to be as long as it needs to be.

As an example, Vikram Seth, the author of the below poem, has written entire novels in poetry. He' s also written them even shorter than below.

All you who sleep tonight

Far from the ones you love,

No hands to left or right,

And emptiness above -

Know that you aren' $t$ alone.

The whole world shares your tears,

Some for two nights or one,

And some for all their years.

\section{Your Turn}

Poetry Exercise

Give writing a poem a shot. It doesn' thave to rhyme unless you want it to.

\section{Your Turn}

\section{Poetry Exercise}

Write a poem about someone who takes a walk in the dark. It doesn' thave to rhyme unless you want it to. 


\section{Your Turn}

\section{Poetry Exercise}

Try your hand at a poem. It can be about anything - your thoughts, feelings, the way a bird looks. The world is full of poetry.

Some writing prompts were reprinted with permission from http://awesomewritingprompts.tumblr.com and http://www. freewritingprompts.net. 